\title{
Os modelos de financiamento de campanha eleitoral e o contexto político-cultural brasileiro ${ }^{1}$
}

\author{
Models of campaign financing the political-cultural Brazilian context
}

\author{
RAÍSSA TONIAL \\ Bacharel em Direito pela PUCRS \\ ELTON SOMENSI DE OLIVEIRA \\ Doutor em Direito pela UFRGS, Professor da Faculdade de Direito da PUCRS
}

\begin{abstract}
RESUMO: A existência de partidos para a representação da vontade política é elemento essencial para a formação do Estado Democrático de Direito e sua efetividade depende de elementos como a existência de recursos financeiros para as campanhas eleitorais. Na busca desses recursos predominam as formas: privado, público, "matching funds" e misto. Este artigo tem por objeto principal a análise destes modelos, suas vantagens e desvios tendo como perspectiva a realidade brasileira, caracterizada por uma cultura patrimonialista. Secundariamente, este artigo também procura identificar elementos que contribuam para disputas eleitorais mais justas e com menores índices de corrupção.

Palavras-chave: Partido político; Representação política; Financiamento de campanha eleitoral; Patrimonialismo.
\end{abstract}

\begin{abstract}
The existence of parties to represent the political will is essential for the formation of a democratic state and its effectiveness depends on factors such as the existence of financial resources for election campaigns. In pursuit of these features predominate forms: public or private matching funds and mixed. This article is primary engaged in the analysis of these models, their advantages and deviations taken the Brazilian reality as perspective, which is characterized by a "patrimonialist" culture. Secondarily, it aims to identify elements that contribute to fairer electoral disputes and lower levels of corruption.
\end{abstract}

Keywords: Political party; Political representation; Financing campaigns; Patrimonialism.

\author{
Cambia lo superficial \\ Cambia también lo profundo \\ Cambia el modo de pensar \\ Cambia todo en este mundo \\ JULIO NUMHAUSER
}

\section{INTRODUÇÃO}

O povo brasileiro pouco viu de uma construção autônoma do espaço público. Em um país enraizado por tradições provenientes da colonização portuguesa, a esfera pública foi construída a partir de valores patriarcais e com sistemas de interferências que tornam a captação de recursos para campanhas eleitorais um momento decisivo na formação de interesses privados no espaço público.

A definição de um modelo ideal de financiamento político partidário não é o objeto principal deste trabalho. A proposta é demonstrar os pontos positivos e negativos dos tipos de captação de recursos existentes e considerá-los no contexto da realidade nacional.

\section{ELEMENTOS DA ATIVIDADE POLÍTICA}

\subsection{Partidos políticos}

\subsubsection{Noções gerais sobre partidos políticos}

O sistema político se caracteriza pela existência de conflitos, seja sobre a distribuição da renda, seja sobre intervenção do Estado na economia ${ }^{2}$, assim, pode se afirmar que o papel do político sobrevive para o estabelecimento da harmonia, da concórdia em um grupo social ${ }^{3}$. Assim, a disputa eleitoral far-se-á em um Espaço político conceituado por Bobbio como $a$ área de conflito que constitui a base da relação entre eleitores e partidos, num dado sistema político e num certo momento histórico ${ }^{4}$. 
Segundo Daniel Shaeffer ${ }^{5}$, a evolução do instituto e da expressão partido político, o tornou inerente à democracia e à estrutura estatal de tal forma que apenas com a sua livre atuação é possível construir um verdadeiro Estado Democrático. Anteriormente utilizava-se o termo $f a c c ̧ a \tilde{a} o^{6}$ para se referir a agrupamentos de oposição ao governo que procuravam influenciar o governo do Estado, englobando assim, todos os grupos políticos existentes ${ }^{7}$. Proveniente do latim, o vocábulo partido tem sentido de fração, de que tudo seria composto de partes. Após a mutação do sentido original, em meados do século XVIII, adquire o significado de participação, partilha ou associação, passando a ser utilizado com a conotação política atual.

É então, à primeira metade do século XIX, que se identificam historicamente, na Europa e nos Estados Unidos, os partidos políticos tal qual concebemos hoje $\mathrm{e}^{8}$. Já os partidos de organização de massa surgem ao final do século de XIX, após o desenvolvimento do movimento operário, iniciados por protestos em prol dos direitos e reinvindicações populares, até a estruturação mais complexa de partido de trabalhadores. É precisamente com o aparecimento dos partidos socialistas - na Alemanha em 1875, na Itália em 1892, na Inglaterra em 1900 e na França em 1905 - que os partidos assumem a posição de organização de funcionários pagos para desenvolver atividade e programa político em nome dos trabalhadores, já que estes não poderiam abandonar seus salários, mesmo que baixos, pelo amor ao debate ou dedicar-se à atividade política em tempo livre, tendo em conta as pesadas jornadas. Neste contexto de profissionalização do político, surgem os problemas de sobrevivência partidária, tema que será analisado em tópico específico.

Como refere Daniel Shaeffer, a primeira definição política para partido pode ser encontrada em Edmund Burke:

Partido é um grupo de homens unidos para a promoção, pelo seu esforço conjunto, do interesse nacional com base em algum princípio particular com o qual todos eles concordam (tradução nossa) ${ }^{9}$.

Gramsci, por sua vez, o define como o organismo social que desempenha as funções que Maquiavel atribuía a uma pessoa singular. Denomina de "moderno Príncipe" o partido político, que age em representação da inteligência e vontade coletiva nas sociedades modernas, mais complexas. Traduzindo a linguagem gramsciana, a tarefa do partido político seria formar uma vontade coletiva nacional-popular, capaz de englobar os clamores de uma nação, em diferentes relações sociais. A conquista da hegemonia política precederia a conquista e a manutenção do $\operatorname{poder}^{10}$.
Portanto, uma explicação para o nascimento e o desenvolvimento dos partidos reside no aumento da demanda de participação de grupos sociais na formação da decisão política, o qual vem à tona em momentos de abalo aos pilares do poder tradicional. Nesta situação são os grupos de representação que se propõe a agir em prol dos estratos menos favorecidos ou excluídos da sociedade, para lhes garantir a ampliação dos poderes políticos. Os partidos canalizam, expressam e representam as reivindicações do povo, tornando-se um alicerce para a realização da democracia.

\subsubsection{Os partidos políticos no Brasil}

A origem dos partidos no Brasil sofreu uma maré de fases partidárias. As disputas de poder se iniciaram por meio de violência e coerção entre duas tradicionais famílias paulistas, os Pires e Camargos. Desde a monarquia, passando pelas Repúblicas, era Vargas, pelo golpe militar de 1964 até a promulgação da Constituição de 1988, os partidos políticos evoluíram em sua autonomia, funcionamento e estabeleceramse essenciais para realização do nosso sistema democrático ${ }^{11}$.

Nesta linha de pensamento, posicionou-se o Supremo Tribunal Federal:

[...] a essencialidade dos partidos políticos, no Estado de Direito, tanto mais se acentua quando se tem em consideração que representam eles um instrumento decisivo na concretização do princípio democrático e exprimem, na perspectiva do contexto histórico que conduziu à sua formação e institucionalização, um dos meios fundamentais no processo de legitimação do poder estatal, na exata medida em que o Povo - fonte de que emana a soberania nacional - tem, nessas agremiações, o veículo necessário ao desempenho das funções de regência política do Estado. As agremiações partidárias, como corpos intermediários que são, posicionandose entre a sociedade civil e a sociedade política, atuam como canais institucionalizados de expressão dos anseios políticos e das reivindicações sociais dos diversos estratos e correntes de pensamento que se manifestam no seio da comunhão nacional $[\ldots]^{12}$.

Assim, a relevância atual dos partidos políticos em nosso país é certificada na Constituição de 1988, sendo literal a condição de filiação para a elegibilidade. Além da autonomia e liberdade que lhes são asseguradas, é a instituição mediadora entre o povo e o Estado no processo de formação da vontade política, principalmente no processo eleitoral ${ }^{13}$.

Os partidos, no papel de instituição mediadora, desempenham funções nos dois âmbitos: do Estado e da sociedade. A doutrina acrescenta o dilema de o 
partido atuar exclusivamente no "âmbito do Estado, enquanto partido do Governo, ou se deverá atuar como organização partidária no âmbito da sociedade"14.

\subsection{Representação política}

O significado e a existência de Representação Política em nossa sociedade é tema intrigante e dispende de um estudo abrangente a cada sistema representativo. Entretanto, vamos nos deter aos principais conceitos que podem ser enquadrados em nossa realidade.

\subsubsection{Noções gerais sobre Representação política}

Detendo-nos ao pensamento gramsciano para definição de política, esta aparece como o conjunto de práticas e objetivações que se refere diretamente ao Estado, nas relações de poder entre governantes e governados ${ }^{15}$.

Outro posicionamento adota Souza Júnior, identificando diferentes níveis de relação entre os dois polos da sociedade política: a Comunidade e o Poder ${ }^{16}$. Um dos níveis, o qual nos interessa neste trabalho, é o Poder como conjunto de órgãos que atua sobre as atividades da Comunidade, conduzindo as ações da sociedade. Esta Comunidade, em um regime democrático, escolhe e alterna os grupos que controlam o Governo, posicionando-se como a Comunidade no Poder, e a relação que se estabelece é entre governantes e governados. ${ }^{17}$

Historicamente, a necessidade de representação surge após a queda de sistemas que não contemplavam qualquer participação política, onde o poder era concentrado na mão de poucos. Somente quando o povo se opôs aos regimes absolutistas a representação surgiu como instrumento político das massas.

Observou-se uma evolução do termo representação na Constituição Francesa de 1791, após a Declaração dos Direitos do Homem em 1789, que condicionou a ação representativa a um plano de políticas públicas voltadas para a vontade estatal, o qual é apresentado à nação durante a campanha eleitoral. A democracia como governo do povo se realizaria apenas através de representantes que atuassem em favor deste e atendessem às urgências da maior parte do país.

Alguns dos conceitos utilizados para caracterizar o exercício da democracia, no caso, a transferência do poder do povo aos seus representantes, elenca divergência de princípios entre Locke e Rousseau: para aquele, o poder deve ser exercido pelos representantes, já para este, o poder deve ser assumido diretamente pelos cidadãos. Conclui-se que o sistema democrático perfeito, porém utópico, seria de um governo do povo para o povo, constituído, simultaneamente, pela democracia formal e pela democracia substancial. ${ }^{18}$
Um ponto crucial da caracterização de um sistema democrático é o de que todos os eleitores devem ser livres em votar segundo a própria opinião formada o mais livremente possivel, isto é, numa disputa livre de partidos políticos que lutam pela formação de uma representação nacional. ${ }^{19} \mathrm{O}$ eleitor, por sua vez, se mostra cada vez menos apegado ao conteúdo ideológico dos partidos políticos e mais atraído pela imagem vendida dos candidatos, propagandeada a cada eleição, culminando numa maior volatilidade do comportamento desse eleitor a cada pleito. Neste sentindo, adentremos no conceito arenoso de financiamento de campanha, que é um dos determinantes da liberdade de escolha do representante.

\subsubsection{A Representação política no Brasil}

Exclama a Constituição em seu artigo $1^{\circ}$, parágrafo único que: "Todo o poder emana do povo, que o exerce por meio de representantes eleitos, ou diretamente, nos termos desta Constituição". A democracia poder ser exercida de duas formas, direta e indiretamente: a) direta, nos casos de plebiscito, referendo e a iniciativa de leis; e b) indiretamente, através dos representantes escolhidos mediante eleição direta e secreta. Entretanto, um dos elementos do Estado Democrático é o processo de escolha dos representantes.

No país, afirma-se um monopólio dos partidos sobre a representação política. Entretanto, não é discutida, ao menos no Judiciário brasileiro, a legitimidade de representação da sociedade pelos partidos. Na verdade, consolida-se este pensamento ainda mais, como podese perceber pela legislação atual, que tenta de certa forma preservar os partidos (ou a sociedade) através, por exemplo, da fidelidade partidária.

Segundo o STF a infidelidade partidária, sem um relevante motivo como o de perseguição política,

[...] subverte o sentido das instituições, ofende o senso de responsabilidade política, traduz gesto de deslealdade para com as agremiações partidárias de origem, compromete o modelo de representação popular e frauda, de modo acintoso e reprovável, a vontade soberana dos cidadãos eleitores, introduzindo fatores de desestabilização na prática do poder e gerando, como imediato efeito perverso, a deformação da ética de governo, com projeção vulneradora sobre a própria razão de ser e os fins visados pelo sistema eleitoral proporcional, tal como previsto e consagrado pela Constituição da República $[\ldots]^{20}$.

$\mathrm{O}$ precedente fortalece o argumento de que a vontade soberana provém da coletividade, dos eleitores, restando, para o STF, dúvida alguma de ser a vontade 
geral representada e realizada pelo mandato partidário.

Apesar da posição do Supremo, hordienamente, a população tem se mostrado insatisfeita com a atuação dos seus representantes, tendo em vista os inúmeros casos de corrupção que são maquinados pelos políticos. Ainda, grande parte da sociedade manifesta-se no sentido de não se sentir representada pelos atuais partidos políticos, facilmente percebido pelos gritos que tomaram às das ruas do país, em uma onda de manifestações, neste ano de 2013.

Entretanto, acreditamos que uma mudança de ideologias partidárias, e até mesmo do sistema político, mesmo que talvez necessárias, não são suficientes para uma transformação de nossa cultura política, uma vez que não atingiria as profundas raízes do patrimonialismo brasileiro, tema que será apresentado no último tópico desde artigo.

\section{FINANCIAMENTO DE CAMPANHA ELEITORAL}

\subsection{Uma perspectiva histórica}

Com a evolução dos partidos políticos e sua indispensável existência no sistema representativo, surgiu a necessidade de manutenção dos grupos partidários, os quais se profissionalizavam a cada dia e necessitavam de maiores quantidades de recursos. Dessa forma, o financiamento das campanhas eleitorais se tornou inerente ao nosso sistema, acabando por possibilitar a realização da democracia.

Assim, adentraremos no tema, expondo, inicialmente, o seu surgimento, para então culminarmos nos modelos de financiamento de campanha eleitoral.

\subsection{1 "Viver para a política e viver da política"}

Os partidos não sobreviveriam sem a captação de recursos financeiros, tanto para o funcionamento ao longo do ano, tanto quanto em época de competição política.

O traço comum das organizações partidárias do século XVIII era a manutenção dos partidos pelos próprios políticos, denominado de autofinaciamento, ou financiamento exclusivamente privado.

A atividade política não era profissionalizada, os representantes viveriam para a política como uma forma de lazer, trabalhando basicamente de forma voluntária, apenas exercendo o status de poder da elite. Quando as classes trabalhadoras começaram a ter acesso a melhores condições socioeconômicas, com o surgimento dos sindicatos na Inglaterra da Revolução Industrial em meados do século XVIII, principiou o surgimento dos chamados partidos de massa, os quais passaram a representar este extrato excluído da sociedade, e a viver da política, profissionalizando-se, e dessa forma, dependendo de algum tipo de subsistência proveniente da própria política. Assim, sobreviviam através de arrecadação de dinheiro de filiados e simpatizantes. Para a manutenção destas doações, os partidos de massa ofereciam serviços sociais, como assistência médica e educacional aos membros.

Tendo em vista que o discurso dos partidos de massa era direcionado a uma única classe, surgiram partidos de discurso universal, que previam o afastamento de conflito ideológico, direcionado o poder à sociedade como um todo, a fim de alcançar um eleitorado cada vez maior. Ainda, percebemos ausência de distinção entre os partidos de situação e oposição, em função da rotatividade de poder entre os principais grupos políticos. Outra mudança deste momento político é a introdução de recursos públicos para financiamento, como também a forte dependência aos recursos oriundos de seus filiados integrantes do governo.

Os termos viver da política e para política foram distinguidos por Max Weber, em sua obra Ciência e Politica: duas vocações. Nessa obra instituiu conceitos capazes de caracterizar a política profissionalizada de nosso tempo.

\subsubsection{Marco histórico das legislações sobre financiamento de campanha eleitoral no Brasil}

O Brasil sempre enriqueceu a sua legislação para estabelecer limites de atuação política. O primeiro regramento que tratou especificamente do financiamento político-partidário foi o Decreto-Lei $\mathrm{n}^{\mathrm{o}} 9.258 / 46$, que proibia o recebimento de apoio (financeiro) proveniente de qualquer fonte estrangeira. Contextualizando, via-se um crescimento dos partidos de viés comunista no Brasil ${ }^{21}$.

Até a década de 50 eram os próprios partidos os responsáveis pela organização das finanças. O Código Eleitoral vigente, Lei $n^{\circ} 1.164 / 1950$, estabeleceu formalidades, como a proibição de doações de autoridades e concessionários de serviços públicos.

Durante o regime ditatorial, o antigo Código Eleitoral foi substituído pela Lei ${ }^{\circ} 4.737 / 1965$ que proibia qualquer doação proveniente de empresas privadas com fins lucrativos para financiamento da campanha. Os recursos eram provenientes de quadro de filiados, detentores de cargos eletivos e doações de pessoas físicas. No entanto, a maior parte era proveniente do Fundo de Assistência Financeira aos Partidos Políticos, o Fundo Partidário, seus valores eram acumulados de multas, doações de pessoas físicas. 
Já a distribuição levava em conta os critérios de desempenho dos partidos nas eleições anteriores, fato que favorecia o partido da situação a Aliança Renovadora Nacional - ARENA, e dificultava os recursos do Movimento Democrático BrasileiroMDB, já que, também, não poderiam receber doações de sindicatos, entidades classistas e empresas privadas.

Durante a vigência da Lei $\mathrm{n}^{0} 5.682 / 1971$, eram os partidos que estabeleciam os limites de gastos na disputa eleitoral. Apesar da intervenção militar no processo eleitoral, o MDB passou a crescer no período de 1974, assim, outros empecilhos foram criados para estagnar a evolução, como a Lei Falcão que proibia a utilização de espaço pago em rádio e televisão e o Pacote de Abril, que empossava candidatos eleitos indiretamente pela Assembleia Legislativa de cada Estado.

A primeira eleição democrática, após a promulgação da Constituição de 1988, elegeu Fernando Collor de Mello como presidente. Neste período, a lei que proibia as doações privadas de empresas e indivíduos, deu margem à prática do caixa-dois. Em nossa primeira eleição nasceu um dos esquemas mais conhecidos da história do país, o esquema PC Farias.

Após o escândalo que resultou na renúncia de Collor o Brasil passou a debater o aumento de gastos na campanha e as lacunas da legislação de fiscalização das verbas arrecadadas. Aumentou o controle e foram fixados limites de doações e sanções para abusos de poder econômico.

A Lei n ${ }^{\circ}$ 9.096/1995 consolidou a legislação sobre os partidos políticos, definindo a origem dos recursos, a distribuição do Fundo Partidário e sua constituição, através de doações e arrecadações de multas eleitorais.

A distribuição dos valores do Fundo foi definida de forma proporcional à representação dos partidos na Câmara dos Deputados, com um pequeno percentual sendo distribuído de forma igualitária a todos os partidos com registro no TSE. Como fontes indiretas de recursos, é disponível o acesso gratuito dos partidos aos espaços de rádio e televisão para a realização da propaganda eleitoral e partidária e a imunidade tributária, disposta no art. 150, inciso VI, alínea "c", da Constituição Federal de 1988.

A Lei das Eleições ( ${ }^{\circ}$ 9.504/1997) restringiu a arrecadação de verbas oriundas de entidades de interesse público, estando sujeita a multa e proibição de contratação com poder público, por descumprimento. No pleito de 2002, a Resolução TSE 20.987/02 enumerou as fontes de recursos, em seu art. 10, passando a consignar como fontes de arrecadação as doações de outros candidatos, comitês financeiros ou partidos políticos, excluída do rol de doações pela Resolução TSE 22.250/06, porém reinserida em 2008, também por meio de resolução ${ }^{22}$.

A Lei 11.300/2006 proibiu doações de entidades beneficentes e religiosas, entidades esportivas que recebam recursos públicos, organizações não-governamentais que recebam verbas públicas e das organizações da sociedade civil de interesse público (OSCIPs). O TSE elaborou as resoluções $n^{\circ} 22.715 / 2006$ e $n^{\circ}$ 23.217/2010, que disciplinam a proibição de doações por cooperativas, cartórios e serviços notariais por todos os tipos de entidades desportivas, não somente as que recebem auxílio de verbas públicas.

Antes disso, em 2005, já no consolidado o Estado Democrático de Direito vem a público o caso Mensalão. $\mathrm{O}$ escândalo envolve quatro dezenas de acusados e dirigentes máximos dos partidos envolvidos. Ao final, foram condenados por diversos crimes, dentre eles, corrupção ativa e passiva.

Nota-se que tanto no caso Collor, como no Mensalão, o país estaria passando por momentos de revolução social, afinal, ao abandonar a Ditadura Militar, estaria libertando-se dos anos de maior concentração de renda, já, durante o governo Lula, o Partido dos Trabalhadores colocaria em prática o proposto em seu manifesto que responderia aos interesses dos trabalhadores. Dessa forma, os escândalos trouxeram, momentaneamente ou não, uma onda de decepção aos brasileiros. Entretanto, não está em evidência neste artigo a atuação dos governos, mas a questão que envolve o país há séculos, a corrupção e os desvios de dinheiro público, que decorrem de uma tradição patrimonialista-estamental: a confusão entre o que é público e o que é privado.

\subsection{Os modelos de financiamento}

Os frequentes escândalos de corrupção política no Brasil vêm sendo relacionados ao tipo de financiamento adotado nas campanhas eleitorais. Historicamente, nosso país evolui a cada eleição em suas normas a respeito da arrecadação de recursos para a promoção de candidatos a cargos eletivos, entretanto, este ainda é ponto fraco do direito eleitoral.

Neste contexto, as dúvidas quanto ao modelo ideal para financiamento são preponderantes. Atualmente, a comissão de reforma política, ao encaminhar o projeto de lei (APJ 2/2011 CEREFPOL - Comissão Especial destinada a efetuar estudo e apresentar propostas em relação à Reforma Política) aprovou o financiamento exclusivamente público para nosso sistema eleitoral, o aprimoramento à fiscalização de gastos, bem como igualdade de concorrência entre os candidatos ${ }^{23}$.

Faremos uma análise sobre os modelos de financiamento atualmente preponderantes nas demo- 
cracias ocidentais, os quais são: o exclusivamente privado ou público, o matching founds e o misto.

\subsubsection{Financiamento privado}

O financiamento privado é o mais antigo entre os modelos de arrecadação de verbas pelos partidos políticos, conforme demonstrando no histórico acima. Consiste, basicamente, na contribuição dos filiados, doações de pessoas físicas ou jurídicas e, ainda, recursos do próprio candidato à sua campanha eleitoral.

Este modelo nos traz argumentos favoráveis ao seu funcionamento no que se refere à natureza dos partidos políticos como associações privadas e de participação voluntária. Assim, os seus filiados e simpatizantes não teriam apenas a solidariedade para o levantamento de recursos, mas também o dever de fomentar o partido com o que considerem necessário. Um dos problemas, referido por Rubio, seria a verdadeira natureza mista dos partidos, de forma quase pública, visto que os partidos assumem posição para assegurar os assuntos da sociedade, deixando de ser questão exclusivamente dos integrantes partidários e passando a ser questão estatal ${ }^{24}$.

Existe a constituição de um poder econômico na formação da decisão do eleitor em detrimento do interesse coletivo, entretanto existe o custo da atividade política, que delimita a livre expressão de posicionamento político. Nessa senda, o custo da democracia atinge outros pilares essenciais para sua realização. À luz desta ideia, explica Cavalcante:

A principal característica que esse tipo de financiamento nos coloca diz respeito à relação entre os doadores e os destinatários desses recursos. Richard Katz e Peter Mair destacam a ação dos financiadores privados de campanhas eleitorais como agentes de pressão sobre os partidos e candidatos ${ }^{25}$.

No campo político pós-eleitoral, a influência econômica pode direcionar os rumos das licitações públicas para o fornecimento de bens e serviços ao governo de forma a favorecer determinados grupos financiadores da campanha, bem como facilitar a concessão de empréstimos, incentivos fiscais e outros benefícios ou, ainda, decisões legislativas e de políticas públicas que favoreçam os grupos econômicos.

Estudos apontam que o dinheiro das doações privadas não compra necessariamente votos, mas sim acesso aos políticos ${ }^{26}$. Há também os apoiadores que fazem as doações aos políticos que já estão alinhados aos seus interesses ${ }^{27}$. Os lobbistas engajados em influenciar as políticas adotadas em benefício próprio, incentivam os gastos eleitorais de candidatos que possam vir a fazê-lo. E estes candidatos, com a ajuda financeira obtida, podem ampliar suas chances de sucesso na disputa eleitoral.

Embora o suporte privado aja como forma de participação, ou "forma de expressão da própria ideologia", como refere Delia, também nos conduz à colonização das estruturas estatais por parte dos poderosos grupos econômicos. Este fato afeta a essência das democracias representativas, tendo em vista que nossos dirigentes deixariam de atuar em prol da coletividade $^{28}$. Além disso, traz algumas considerações possíveis de serem respondidas frente aos corriqueiros escândalos envolvendo políticos e empresas privadas, escancarados nos últimos tempos.

\subsubsection{Financiamento público (direto e indireto)}

Após a Segunda Guerra Mundial as constituições incorporaram os partidos políticos como instituições fundamentais da democracia. Sendo assim, os partidos passaram a ter maior enraizamento com o Estado (o garantidor de seu funcionamento) e a receber recursos provenientes deste, por meio do financiamento público. Este consiste no ingresso dos recursos estatais para partidos e candidatos, de forma direta ou indireta. $\mathrm{O}$ ingresso direto é a transferência dos recursos diretamente do orçamento nacional. Já o financiamento indireto, são os incentivos concedidos pelos governos aos candidatos e partidos políticos, como a imunidade de impostos para funcionamento dos serviços partidários, espaço televisivo e via rádio gratuitos, para divulgação das propostas e candidatos, como forma de campanha eleitoral. Ainda, temos como exemplo a cessão de espaços públicos para as manifestações partidárias ${ }^{29}$.

O financiamento público visa a menor influência do particular nas funções partidárias. Tem como objetivo principal a maior fiscalização dos gastos e, consequentemente, da corrupção, bem como a igualdade na disputa partidária, não permitindo que os partidos se tornem vítimas de interesses econômicos ${ }^{30}$.

Um dos objetivos do modelo público é o maior nível possível de equidade entre os competidores de forma a possibilitar um nível de escolha desapegado do vultuoso marketing despendido nas campanhas. Assim, os candidatos seriam eleitos por preferência dos eleitores ao plano de governo proposto,

e não em função de maiores ou menores recursos financeiros, que poderiam transformar os processos eleitorais em meros ritos democráticos, com ganhadores e perdedores pré-determinados. A intenção é conjurar, até onde seja possível, os riscos palpáveis que significa para a competição democrática o fato de que os partidos possam ser prisioneiros de grandes agentes do mercado, ou inclusive, de grupos de interesse que operam à margem da legalidade" ${ }^{\prime 31}$. 
O modelo também ajudaria no fortalecimento e institucionalização dos partidos políticos nos sistemas democráticos representativos. Na América Latina, a doutrina se rende à tese que vê os partidos como associações privadas cumprindo funções públicas ou de interesse geral, devendo, portanto, ser objetos de financiamento público.

A fórmula utilizada para distribuição dos recursos públicos leva em conta a composição dos partidos políticos, por exemplo, o desempenho na eleição anterior, número de cadeiras ocupadas no parlamento, posições majoritárias conquistadas, dentre outros aspectos. Como se percebe em qualquer sistema, o financiamento público também possui pontos fracos, sendo um dos aspectos a possibilidade de "congelamento" dos partidos políticos, em razão da fórmula adotada, o que dificulta a entrada de pequenos ou novos partidos na competição eleitoral, em razão de sempre haver um concorrente em melhor posição, normalmente os mais tradicionais.

Zovatto acrescenta que a estatização excessiva aliada à dependência econômica total dos recursos estatais ocasionará o distanciamento do partido de sua base, diminuindo o número de filiações e aumentando a burocratização e ossificação dos partidos. Ainda, esta forte dependência repercutirá em uma diminuição da liberdade partidária no distanciamento da mutante realidade social.

Rubio argumenta que o preço da democracia será excessivo aos países com altos índices de misérias, pobreza, tendo em vista que parcela do orçamento público aos partidos deverá ser majorada. Segundo o autor, a proibição dos aportes privados tem outras consequências negativas, uma delas é que o suporte privado continuará a existir por meios ilegais, contas bancárias no estrangeiro, pessoas interposta, por exemplo, fora de qualquer possibilidade de controle e transparência, pois não olvidemos que sempre haverá indivíduos ou grupos interessados em apoiar financeiramente os partidos ${ }^{32}$.

Este sistema também possibilita que o governo de situação utilize de manobras de exclusão aos grupos de oposição, prejudicando a atuação política. Outro óbice é formação de partidos de fachada, interessados na verba púbica distribuída de forma igualitária, desinteressados de enraizamento na sociedade, tornando-se mais um negócio que instituição política representativa ${ }^{33}$.

Portanto, além de uma distribuição que vise o desempenho anterior dos partidos servir de manutenção ao status quo, também traz o risco de criar parasitas do fundo partidário, como decorrência da oportunização do recebimento igualitário de recursos.

\subsubsection{Financiamento em contrapartidas (matching funds)}

O sistema de matching, inserido na Alemanha em 1994, pode ser visto por alguns como financiamento público, porém, aqui, os fundos estatais não podem ser superiores aos recursos privados.

Nesse modelo o candidato recebe dos cofres públicos um montante proporcional ao arrecadado de suas fontes privadas, servindo como uma complementação a essas doações, que podem sofrer limitações entre montantes máximo e mínimo, de forma a obrigar a dar preferência às pequenas contribuições, porém numerosas, em lugar de poucas e exorbitantes quantias de dinheiro. Em busca de recursos, os partidos se associam à sua base eleitoral, pois haverá uma aproximação entre o número de eleitores e o número de doadores, fortalecendo o enraizamento social dos partidos políticos.

Ainda, sendo a porcentagem proveniente dos cofres públicos condicionada à captação de recursos pelos próprios partidos, estes irão preferir trabalhar na legalidade para obtenção de verba, declarando todos os rendimentos recebidos, o que facilita o controle de caixa dois e de outros meios ilegais que visam a manutenção do poder por meio econômico.

Entretanto, acentua Cavalcanti alguns pontos negativos. Em razão da doação de recursos limitados e de um rol restrito de doadores, estes teriam maior influência sobre os competidores. Ainda, os candidatos eleitos poderiam ver-se ainda mais dependentes das fontes de financiamento, o que cria incentivos à troca de favores entre as partes.

\subsubsection{Financiamento misto}

A adoção do financiamento simultaneamente público e privado para o financiamento partidário tornou-se muito comum para as constituições posteriores à Segunda Guerra Mundial ${ }^{34}$. Com exceção da Venezuela, que em 1999 aboliu o financiamento público de campanhas, os demais países da América Latina aderiram ao sistema misto de financiamento.

O financiamento misto tem a vantagem de manter a aproximação da militância, filiados, simpatizantes e da própria sociedade aos partidos. Além disso, mantém a autonomia dos partidos em relação ao Estado, sem perder o caráter público de representação do "povo" ou comunidade, em razão dos aportes estatais como parte da fonte financiadora.

Sendo assim, a maioria das democracias adota este modelo, até mesmo como forma buscar inserir apenas "lado positivo" dos modelos exclusivos. 
Entretanto, sabemos que os prejuízos são inerentes a qualquer sistema que se opte, sendo possível apenas a amenização, mas não abolição dos malefícios.

\section{O FINANCIAMENTO NO BRASIL HOJE}

O país ainda segue o modelo misto de financiamento. A Lei dos Partidos Políticos define o Fundo Partidário como provedor do financiamento público. No art. $1^{\circ} \mathrm{da}$ Lei n ${ }^{\circ} 11.459$, de 21 de março de 2007, estabelece uma parcela de 5\% do Fundo a ser distribuído igualmente a todos os partidos registrados no TSE, e $95 \%$ do total distribuídos proporcionalmente ao número de votos obtidos nas últimas eleições para Câmara dos Deputados.

Ademais, permite doações privadas, oriundas de pessoas físicas ou jurídicas, às campanhas, conforme dispõe o art. 20 da Lei $n^{\circ}$ 9.504/1977.

\subsection{Doações de pessoas jurídicas}

A partir de 1998 as doações foram limitadas a $2 \%$ do faturamento bruto auferido no ano anterior ao da realização das eleições. O candidato pode utilizar em favor de sua própria campanha eleitoral o valor equivalente ao limite de gastos que informou à Justiça Eleitoral no momento da realização do registro de sua candidatura.

Para a eleição de 2012, o TSE inseriu mais uma norma na Resolução $n^{\circ} 23.376^{35}$, frisando que "é vedada a realização de doações por pessoas jurídicas que tenham iniciado ou retomado as suas atividades no ano-calendário de 2012, em virtude da impossibilidade de apuração dos limites de doação constante do inciso II do caput".

O doador que fizer repasse de valores acima dos limites permitidos ficará sujeito ao pagamento de multa de 5 a 10 vezes a quantia em excesso. Além disso, a pessoa jurídica que infringir este artigo poderá ficar proibida de participar de licitações e de celebrar contratos com o poder público pelo prazo de 5 anos. O candidato, por sua vez, poderá responder por abuso de poder econômico e, em alguns casos, ter seu mandato cassado $^{36}$.

Em eleições majoritárias as maiores doações são realizadas diretamente ao candidato e chegam até um milhão de reais. Destacam-se como maiores responsáveis pelas vultuosas quantias doadas as empresas metalúrgicas, construtoras, engenharias, empreiteiras e distribuidoras de materiais de limpeza ${ }^{37}$. A conclusão que podemos chegar para o tipo de doadores preponderantes são fornecedores de atividades e produtos que o Governo costuma contratar e licitar.

\subsection{Doações de Pessoas Físicas}

A partir das eleições de 1998, com a promulgação da Lei 9.504/97, as doações estão limitadas a 10\% dos rendimentos brutos auferidos no ano anterior ao das eleições. A partir do pleito de 2010 houve uma exceção, que são as doações estimáveis em dinheiro relativas à utilização de bens móveis ou imóveis de propriedade do doador, desde que o valor da doação não ultrapasse $\mathrm{R} \$ 50.000,00$ (cinquenta mil reais).

Apesar da preponderância em doações originadas de empresas, existem doações de pessoas físicas, filiados, militantes e até dos próprios candidatos, que perfazem normalmente o valor de trinta, chegando a mil reais.

\section{A CULTURA PATRIMONIALISTA BRASILEIRA}

O termo patrimonialismo foi empregado no Brasil para caracterizar as apropriações privadas dos recursos e interesses públicos em diversos setores, conforme explica Sorj. No âmbito político, a cultura patrimonialista pode ser percebida pela utilização dos cargos eletivos ou executivos para obtenção de vantagens econômicas, orçamentárias, favores aos setores privados, licitações armadas com superfaturamento de contratos. No funcionalismo público, denota-se pela repressão, regulamentação para receber propinas e comissões. Ainda, identifica Sorj, o patrimonialismo negativo, que consiste no uso do poder público para discriminação de grupos sociais, através do sistema policial e judiciário, os quais tem preferência à marginalização do setor mais pobre da população $0^{38}$.

Já para Lenio Streck o Estado é patrimonialista quando os titulares do poder se apoderam do aparelhamento estatal, gerando uma quase indistinção do que é bem público e bem privado. Caracteriza a apropriação privada dos recursos estatais, tanto por políticos, funcionários públicos e setores privados. Já o estamento, é o que dá forma ao exercício patrimonialista de poder. Além do binômio ser detectado em processos de privatização no país, enfrentemos o tema como uma das causas da corrupção e aparelhamento político ${ }^{39}$.

Apesar das diversas posições teóricas adotadas pelos autores que conceituam patrimonialismo, as consequências nos parecem semelhantes. A obra "Raízes do Brasil", publicada em 1936, demonstra a característica fundamental do "homem cordial" brasileiro, que em sua precária vida pública era fortemente inclinado a não diferenciar os seus interesses privados e a coletividade que o cercava ${ }^{40}$. Em Sergio 
Buarque de Holanda, o patrimonialismo se consagra na medida em que os laços familiares transcendem à esfera privada invadindo a pública. Família e Estado devem ser opostos, pois pertencem a ordens distintas, para que haja o triunfo do público sobre o particular.

O sociólogo alemão Max Weber define patrimonialismo como um tipo de dominação tradicional, onde a obediência ao detentor do poder sobrevém de uma tradição arraigada - "porque sempre foi assim". O governante exerce o poder político sobre determinado território, amparado por uma administração eleita por ele de forma pessoal, pautada na confiança. Não há dissociação dos funcionários que cuidam da vida particular do governante e os que exercem as funções administrativas estatais:

No patrimonialismo, o governante trata toda a administração política como seu assunto pessoal, ao mesmo modo como explora a posse do poder político como um predicado útil de sua propriedade privada. [...] Os funcionários, por sua vez tratam o trabalho administrativo, que executam para o governante como um serviço pessoal, baseado em seu dever de obediência e respeito. ${ }^{41}$

Destarte, é na obra os "Donos do Poder", que a inserção da cultura patrimonialista no Estado brasileiro é analisada de forma singular. Raymundo Faoro, com maestria, encontra explicação para as lacunas do Estado e da Nação pátria em nossa formação histórica e identidade política através do prolongado domínio do patronato do estamento burocrático mais precisamente, na colonização lusitana.

Elucida o jurista a inexistência de distinção entre os bens privativos do príncipe e o bem público em um tom de quase total indiferença por parte da coroa. Portugal construiu um Estado cuja propriedade se confundia com o domínio da casa real e ao longo do império o poder continuou sendo o estado - "o governo tudo sabe, administra e prevê" 42 .

Defende Faoro, que o modelo institucional tinha como forma de organização política um patrimonialismo regido pelo poder administrativo do príncipe, e este sustentado numa base sólida de funcionários e súditos que utilizava do Estado em caráter particular. Essa elite que administrava os poderes reais formava o estamentoburocrático, conforme a concepção weberiana. Tais estamentos apoiam-se na desigualdade social, tendo para si privilégios que os mantém no poder ${ }^{43}$.

Segundo Faoro, os estamentos governam, as classes negociam. Os estamentos são órgãos do Estado, as classes são categorias sociais (econômicas) ${ }^{44}$. Assim, os estamentos se apropriam do Estado, cargos e funções, para satisfazer interesses particulares. Os interesses do Estado vão ao encontro dos interesses da camada que o dirige e se apropria do conceito de coletividade, traduzindo o particularismo como sendo o geral.

O fortalecimento dos "donos do poder" se dá pela manutenção da dependência do povo em relação à atuação estatal em todos os setores. $\mathrm{O}$ indivíduo não vê necessidade de atuar politicamente, pois inculto, ausente de interesses pela coisa pública, confiante na bússola do governante, que se compromete a prover a cura para as necessidades sociais. O Estado superprotetor visa a manter nas mãos dos dirigentes o destino da nação ou dos bens públicos ${ }^{45}$.

Nas palavras de Faoro, o Estado torna-se o pai do povo - D. João I, D. Pedro II ou Getúlio Vargas - pois busca a adesão das massas através da política social de bem-estar. Do outro lado da pirâmide espera o povo, pede e venera, transformando seus anseios e clamores em política de salvação ${ }^{46}$.

Um viajante norte-americano da década de 20 , irritado e furioso, caricaturou, forçando as linhas e as cores, o quadro que supusera ver. "Existe no Brasil" - clama o profeta puritano - "uma massa desarticulada a que chamarei de 'povo'. É completamente analfabeta. Por isso, não tem padrão próprio de agricultura, zootecnia ou arquitetura. Tem uma ideia muito vaga do resto do mundo a que alguns chamam englobadamente de 'Paris'. Não toma parte na administração pública. Desprovida de terras; em sua maioria, trabalhando por conta de outrem: o patrão ou o chefe político. 'Existe, porém', - continua cada vez mais irado -, "outra classe altamente articulada a que chamarei de 'traidores do povo'. São letrados, capazes de compor frases sonoras. ... Conhecem o conforto das moradias arejadas. Sabem muito mais a respeito do resto do mundo que de seu próprio país. O governo é a missão para a qual julgam ter nascido" ${ }^{47}$.

Os brasileiros desprovidos de instrução não possuem articulação em associar-se em prol de objetivos em comum para findar suas urgências, que tornam-se apenas individuais e inesgotáveis, pois acabam por resumir-se em carências cotidianas. Enquanto isso, os detentores de poder, seja econômico, seja político, manipulam e definem os anseios dessa sociedade, e o povo dentro da engrenagem a move através da força física, não reluta, nem interfere no resultado.

Apesar do coronelismo não ter desaparecido, a crescente urbanização e transformação das relações sociais no campo, transferiu em sua maior parte o poder dos coronéis aos governantes, através da cooptação de eleitores por diversos meios, seja carismática, em razão do poder, marketing, etc. A promoção pela busca do poder revela-se em um bombardeio em tempo de eleição. 
O moderno Brasil vive os reflexos da herança lusitana: desvirtuamento da finalidade dos recursos em atender as urgências da sociedade, má distribuição de renda, indiferença dada às políticas sociais, bem como impunidade da elite econômica. O patrimonialismo contemporâneo passa a ser percebido como a primeira fonte de problemas sociais e de violação à justiça, igualdade e democracia e estará presente de alguma forma, seja ínfima ou faraônica, em todas as sociedades onde a distribuição de riquezas e poder é desigual ${ }^{48}$.

Dessa forma, o país jamais se divorciou do patrimonialismo. Se por um lado avança economicamente, expande as relações comerciais, decresce no índice de desemprego e cria modernas instituições de administração, as camadas dirigentes e políticos ainda utilizam de suas posições para assegurar vantagens pessoais, bem como para o favorecimento de bases políticas e licitações a grandes núcleos empresariais.

\section{DINHEIRO VERSUS DEMOCRACIA}

Dinheiro versus Democracia: pode ser sinônimo de competição acirrada, mas com vencedor préestabelecido. É quase indiscutível que a quantidade de votos recebidos depende da quantidade de dinheiro utilizado no marketing eleitoral, dentre outros aliados, que até hoje são pertinentes na cultura brasileira, como a compra de votos. Apesar da existência de vetos quanto os gastos, como por exemplo, em realização de showmícios e distribuição de cestas básicas ${ }^{49}$, o vultuoso marketing polui os olhos dos cidadãos a cada eleição.

Ramayana aduz que não importa o fato de ser eleito ou não para comprovar a desigualdade na competição política: a propaganda abusiva já contribui no desequilíbrio entre participante através da extrapolação de limites às doações privadas em campanhas eleitorais ${ }^{50}$.

A literatura aponta que os altos gastos fortificam a corrupção, transformando o "período democrático" em apenas mais um negócio de lucro, visto que não há qualquer ideologia por parte da maioria dos financiadores, principalmente dos grandes grupos econômicos, uma vez que em uma mesma campanha doam as mesmas exorbitantes quantias para os concorrentes mais fortes, vinculados aos partidos tradicionais, com mais tempo de propaganda gratuita, ou seja, com maior chance de eleição.

Fleischer corrobora na argumentação, afirmando que os enormes gastos ocorrem em maior parte em razão do sistema eleitoral adotado no país, incentivando a competição árdua entre os companheiros de mesma chapa $^{51}$. No Brasil o sistema utilizado é de lista aberta, não há patamar fixo de distribuição de cadeiras, subrepresentando os mais populosos e super-representando os menos populosos, geralmente mais pobres ${ }^{52}$.

Mainwaring argumenta que a liberdade e individualismo dos políticos em relação às ideologias partidárias são um dos pilares fundamentais de um sistema político elitista e patrimonialista, no qual a maioria dos políticos se apropria privadamente dos bens públicos:

Na ausência de partidos minimamente disciplinados, os políticos podem defender os barões do açúcar do Nordeste, os reis do café do Sul, os fabricantes de calçados de São Paulo, as grandes empresas estatais de Minas Gerais - mesmo às custas da res publica e mesmo quando fazer isso vai de encontro aos programas e plataformas partidários. Os políticos, suas famílias e seus amigos se beneficiam enormemente com esse sistema, da mesma forma que a elite econômica do País, que teve estreitas ligações pessoais, familiares e financeiras com uma grande parte da classe política ${ }^{53}$.

Sustenta o cientista que, para a maioria dos políticos brasileiros, a representação significa mais clientelismo $^{54}$, arraigado no país, do que representação clara dos grupos sociais definidos.

Polêmicos casos surgem na esfera nacional que demonstram a quem os governos representam e os reais interesses dos investidores de campanha. Um exemplo é o Novo Código Florestal, aprovado pelo Congresso Nacional em meados de setembro de 2012. O Código prevê normas favoráveis aos agropecuaristas, e segundo os estudiosos, causará imensos impactos ambientais. Segundo nota publica em veículo de informação, o Deputado Paulo Piau (PMDB-MG), assim como muitos outros deputados da bancada ruralista, teve sua campanha financiada por produtores rurais, esperançosos pela aprovação do Código e manutenção de seus interesses.

As críticas à Piau esquentaram quando o deputado Chico Alencar (PSOL-RJ) afirmou que Piau teve campanha eleitoral financiada por empresas da produção agropecuária, ferindo o Código de Ética da Câmara, que considera atentado ao decoro parlamentar relatar matéria de interesse específico de pessoas ou empresas que tenham contribuído para a campanha do parlamentar. Segundo o PSOL, Piau recebeu mais de R $\$ 990$ mil destas empresas, o que corresponde a $41,7 \%$ dos $\mathrm{R} \$ 2.380 .528$ que declarou ter recebido em doações. O requerimento não foi aceito pelo plenário. Ao término da sessão, Piau saiu-se com essa: "O financiamento privado de campanha é permitido no Brasil”"55. 
De fato, como alega o Deputado, não há qualquer crime nas doações, entretanto, abre margem para discussões sobre as verdadeiras intenções dos financiadores partidários. Vê-se que ambientalistas e biólogos repudiaram a norma ambiental com todas as suas forças e lutaram pelo veto direto do Palácio da Alvorada, entretanto, a legislação foi aprovada.

Além da crise da representação demonstrada, a desigualdade entre os concorrentes de modo a influenciar na competição democrática fere o disposto no art. 14, parágrafo $9^{\circ}$, da Constituição ${ }^{56}$ de 1988 , que protege a legitimidade das eleições, através da não influência do poder econômico e trata o abuso deste poder como violador à probidade administrativa e à moralidade para o exercício do mandato.

A norma constitucional revela a preocupação com as desigualdades existentes entre os candidatos que disputam o pleito eleitoral, a ponto de proibir determinadas condutas, buscando com isso assegurar o mínimo de igualdade de oportunidades aos candidatos e ao eleitor o exercício do direito de voto de forma livre. Adotado na Constituição de 1988, o princípio da igualdade impede a criação de tratamentos abusivamente diferenciados a pessoas que se encontram em situações idênticas.

A doutrina alemã discute com substância o tema acerca dos modelos de financiamento e sobre o princípio da Chancengleicheit (igualdade de chances). Corrobora Hesse, aduzindo que o financiamento público conduz à independência da influência de patrocinadores privados e oportuniza a igualdade de chances, entretanto pode acrescentar dúvida a tarefa dos partidos, que são livres e não-estatais ${ }^{57}$.

Pelo motivos expostos, muitos autores são a favor do financiamento exclusivamente público para as campanhas eleitorais.

Relator da proposta de Reforma Política no país e principal militante do modelo exclusivamente público, o Deputado Petista Henrique Fontana aponta que os gastos eleitorais seriam decisivos nas campanhas. Conforme os dados finais disponibilizados pelo Tribunal Superior Eleitoral em relação à campanha para a Prefeitura Municipal de Porto Alegre-RS em 2012 (Tabela 1) o candidato eleito, José Fortunati, do Partido Democrático Trabalhista - PDT, gastou aproximadamente mais de 2 milhões de reais a mais que a segunda candidata mais votada, Manuela D'Avila, do Partido Comunista do Brasil - PC do B.

Argumenta, o deputado, que o modelo proposto possibilita campanhas mais baratas, e o financiamento livre de interesses que não seja os legítimos de uma representação política, fortalecendo a independência dos candidatos frente aos seus doadores.

Seria criado um Fundo de Financiamento de Campanhas Eleitorais responsável por distribuir os recursos orçamentários aos candidatos de acordo com uma árvore que define o montante destinado para cada cargo em disputa, de acordo com Estado e Município. Após, os recursos seriam distribuídos entre os partidos proporcionalmente aos votos obtidos nas eleições anteriores, ou seja, de forma igualitária primeiramente, e depois de acordo com o desempenho na disputa pelo poder.

Entretanto, o sistema proposto influencia diretamente o status quo e a concentração partidária, favorecendo os partidos tradicionais, arraigados à sociedade, além de possibilitar a transformação de único bloco partidário ${ }^{58}$.

Ainda, afastar o financiamento privado não traria segurança de que este deixaria de ocorrer de forma ilegal, pois devemos contextualizar a realidade brasileira, construída sob uma cultura lusitana, de heranças patrimonialistas, que promovem o privado sobre o público, tanto na manutenção do poder como na obtenção de vantagens particulares em detrimento da sociedade. E é justamente nas raízes históricas que se consolidam os resultados de hoje.

Tabela 1. Eleição 2012 - Prestação de contas final

\begin{tabular}{llccc}
\hline \multicolumn{1}{c}{ Candidato } & \multicolumn{1}{c}{ Legenda } & Receita (R\$) & Despesa (R\$) & Votos válidos \\
\hline José Fortunati & PDT/12 & $6.247 .148,32$ & $6.247 .148,32$ & 517.969 \\
Manuela D'Avila & PC do B/65 & $3.915 .932,12$ & $4.538 .457,80$ & 141.073 \\
Adão Villaverde & PT/13 & $2.500 .017,94$ & $3.978 .585,34$ & 76.548 \\
Roberto Robaina & PSOL/50 & $81.377,00$ & $81.293,39$ & 30.577 \\
Wambert Di Lorenzo & PSDB/45 & $305.056,83$ & $457.506,68$ & 19.514 \\
Jocelin Azambuja & PSL/17 & - & - & 4.412 \\
Érico Correa & PSTU/16 & $45.398,50$ & $45.398,50$ & 4.122 \\
\hline
\end{tabular}

Fonte: a autora. Dados: TSE. 


\section{CONSIDERAÇÕES FINAIS}

Discorremos sobre os pontos positivos e negativos dos modelos de financiamento. O modelo privado nos traz a aproximação do partido à base eleitoral e autonomia quanto ao Estado, fortalecendo o sistema partidário através das doações de filiados. Entretanto sofrem influência dos grupos econômicos interessados nos rumos da vontade política do país.

Como contraponto, propõe-se o financiamento público como solução. No entanto, além de não garantir o fim do recebimento de aportes privados por meios ilegais, os partidos tradicionais poderiam ser mais privilegiados, de acordo com o sistema de distribuição do Fundo adotado, fortalecendo a ossificação dos partidos junto ao Estado, bem como o enfraquecimento dos novos.

Já o sistema matching funds traz grandes expectativas. Aproxima o partido da sociedade, dando valor às pequenas e numerosas contribuições e incentivando a transparência. Entretanto, poderia estreitar ainda mais os laços entre doadores e candidatos a ponto de os deixar dependentes dos financiadores de campanha, o que torna-se incentivo à forte troca de favores. Nossa sociedade não estaria habilitada a receber este "encargo" de proximidade com partidos e candidatos, já que o enraizamento do patrimonialismo na cultura brasileira afastou a atuação do cidadão na vida política do país.

A manutenção da dependência do povo quanto à atuação do estado para a resolução de todos os clamores fortalece a existência dos donos do poder, interessados em levar a sua vontade como de toda uma nação. $\mathrm{O}$ favorecimento consciente de interesses particulares provém de um individualismo corrente em nossa cultura patrimonialista, além disso, é a maior fonte de corruptores. Dessa forma, não parece haver como, partindo exclusivamente da análise dos modelos de financiamento, chegar-se a conclusão exata de qual deveria ser o adotado em nosso país. Esta pesquisa aponta um estudo que considere o financiamento de campanha em conjunto com a análise das nossas instituições, tendo em conta a ética e a solidariedade em nossa cultura.

Para uma maior possibilidade de controle, fiscalização, e um comprometimento dos órgãos responsáveis, não bastaria simplesmente a reforma na legislação vigente, tendo em vista que os problemas transcendem a letra de lei e vão ao encontro de nossas instituições e cultura. Não serão, portanto, nossas principais urgências solucionadas com a reforma de um documento normativo, mas pela busca de uma maneira de reconstruir a forma de fazer política, talvez a própria política, não como um fim em si mesmo, mas como modo de buscar-se o bem comum e a real justiça social.

\section{REFERÊNCIAS}

ARAÚJO, Caetano Ernesto Pereira de. O monopólio dos partidos sobre a representação política. Revista de Informação Legislativa: Reforma politica, Brasília, ano 41, n. 161, jan./mar. 2004.

BOBBIO, Norberto, MATTEUCCI, Nicola; PARQUINO, Gianfranco. Dicionário de Política. 11. ed. Brasília: UNB, 1998. v. 1.

BOURDOUKAN, Adla Youssef. O bolso e a urna: financiamento político em perspectiva comparada. 2009. 152 f. Tese (Doutorado em Ciência Política) - Departamento de Ciência Política, Faculdade de Filosofia, Letras e Ciências Humanas, Universidade de São Paulo, São Paulo, 2009.

BRASIL. Constituição da República Federativa do Brasil de 1988. Brasília, DF: Senado Federal, 1988. Disponível em: <http://www. planalto.gov.br/ccivil 03/constituicao/ConstituicaoCompilado. htm>. Acesso em: 23 out. 2012

Relatório do projeto de lei para reforma política. Dispõe sobre o sistema eleitoral para as eleições proporcionais e sobre o financiamento público exclusivo das campanhas eleitorais. Brasília, DF: Câmara dos Deputados, 2011. Disponível em: $<$ http:// www.henriquefontana.com.br/henriquefontana/arquivos/folderprojects?folder_id=196040>. Acesso em 23 set. 2012.

Supremo Tribunal Federal, Pleno. Mandado de Segu$\overline{\text { rança }}^{\circ}$ 26.603/DF, Rel. Min. Celso de Mello, j. 04/10/2007. Disponível em: <http://www.stf.jus.br/portal/processo/verProcesso Andamento.asp?incidente $=2513846>$. Acesso em: 25 out. 2012 .

Tribunal Superior Eleitoral. História das eleições no Brasil. Disponível em: $<$ http://www.tse.jus.br/hotSites/biblioteca/ historia das eleicoes/capitulos/partidos politicos/partidos.htm>. Acesso em: $\overline{0} 8$ out. 2012.

Tribunal Superior Eleitoral. Resolução $n^{\circ}$ 23.376. Brasília. Disponível em: <http:/www.eleitoralbrasil.com.br/imagens/ textos/files/Resolucao\%20TSE\%2023376\%20-\%20Arrecadacao $\% 2 \mathrm{C} \% 20$ gastos $\% 20 \mathrm{e} \% 20$ prestacao $\% 20 \mathrm{de} \% 20$ contas.pdf $>$. Acesso em: 25 out 2012.

BURKE, Edmund. Thoughts in the cause of the presente discontents (1770) em The works of Edmund Burke. In: CHARLOT, Jean. Os partidos politicos. Brasília: Universidade de Brasília, 1982. Apud: SELL, Daniel Shaeffer. Estado de Partidos: a solução para a crise de representação política no Brasil. Resenha Eleitoral: nova série, Florianópolis, TRE-4a Região, v. 15, (ed. esp.), 2008.

CAVALCANTE, Carlos Vinicios de Oliveira. O custo da democracia: o financiamento privado das campanhas para o Senado em 2010 e suas implicações à competição política. 2011. 143 f. Dissertação (Mestrado em Ciências Sociais) - Faculdade de Filosofia e Ciências Humanas, Pontifícia Universidade Católica do Rio Grande do Sul, Porto Alegre, 2011.

COUTINHO, Carlos Nelson. GRAMSCI: um estudo sobre seu pensamento político. 3. ed. Rio de Janeiro: Civilização Brasileira, 2007. FAORO, Raymundo. Os donos do poder: formação do patronato politico brasileiro. 4. ed. Porto Alegre: Globo, 1977. v. 1.

Os donos do poder: formação do patronato político brasileiro. 3. ed. Porto Alegre, 1976. v. 2

FLEISHER, David. Reforma política e financiamento das campanhas eleitorais. p. 79-103. In: SPECK, Bruno Wilheilm; ABRAMO, Cláudio Weber; SILVA, Marcos Fernandes G. da; FLEISHER, David; NASSMACHER, Karl Heinz. (Orgs.). Os custos da corrupção. São Paulo: Fundação Konrad Adenauer Stiftung, 2000. (Cadernos Adenauer, 10).

HESSE, Konrad. Elementos de Direito Constitucional da República Federal da Alemanha. Tradução de Dr. Luís Afonso Heck. 20. ed. Porto Alegre: Sergio Antônio Fabris Editor. 1998. (Original alemão: Grundzüge des Verfassungsrechts der Bundesrepublik Deutschland). INSTITUTO ANTÔNIO HOUAISS DE LEXICOGRAFIA. Mini dicionário Houaiss da língua portuguesa. Rio de Janeiro: Objetiva, 2010. $956 \mathrm{p}$. 
LIMITES DE DOAÇÃO. Eleitoral Brasil. Florianópolis. Disponível em: $<$ http://www.eleitoralbrasil.com.br/index.php/txt/ler/18>. Acesso em: 17 set. 2012.

MAINWARING, Scott. Políticos, partidos e sistemas eleitorais: o Brasil num perspectiva comparativa. Tradução de Otacílio F. Nunes Jr. Estudos Eleitorais, Brasília: TSE, v. 1, n. 2, maio/ago. 1997.

MANSUR, Vinícius. Decisão sobre o Código Florestal é adiada. Carta Maior, São Paulo-SP, em 25.04.2012. Disponível em: $<$ http:// www.cartamaior.com.br/templates/materiaMostrar.cfm?materia $\mathrm{id}=20028>$. Acessado em: 15 out. 2012.

MENDES, Gilmar Ferreira; COELHO, Inocêncio Mártires; BRANCO, Paulo Gustavo Gonet. Curso de direito constitucional. 5. ed. rev. atual. São Paulo: Saraiva, 2010.

MOTA, Guilherme Carlos. Ideologia da cultura brasileira: 19331974. 9. ed. São Paulo: Ática, 1994.

PORTUGAL, Adriana Cuoco. Lobby pré-eleitoral e financiamento público de campanhas eleitorais: uma exploração em economia política positiva. 2006. 150 f. Tese (Doutorado em Ciências Econômicas) - Faculdade de Economia, Administração, Contabilidade e Ciência da Informação e Documentação, Universidade de Brasília, Brasília, DF, 2006.

POTTERS, Jan; SLOOF, Randolph. Interest groups: A survey of emprirical models that try to assess their influence. In: European Journal of Political Economy, v. 12, p. 412, 1996. Disponível em: $<$ http://arno.uvt.nl/show.cgi?fid=59708>. Acesso em: 08 out. 2012. RAMAYANA, Marcos. Direito eleitoral. 8. ed. Niterói-RJ: Impetus, 2008.

RUBIO, Delia Ferreira. Financiamento de partidos e campanhas Fundos públicos versus fundos privados. Novos Estudos CEBRAP, n. 73 , nov. 2005.
RUBIO, Delia Ferreira. Financiamiento político en el Cono Sur. In: GRINER, Steven; ZOVATTO, Daniel. (Orgs.). De las normas a las buenas prácticas: el desafío del financiamiento político em América Latina. San José de Costa Rica: OEA-Idea, 2004.

SCHLICKMANN, Denise Goulart. Financiamento de campanhas eleitorais. 5. ed. Curitiba: Jiruá. 2010.

SELL, Daniel Shaeffer. Estado de partidos: a solução para a crise de representação política no Brasil. Resenha Eleitoral: nova série, Florianópolis, TRE-4a Região. v. 15, ed. esp. 2008.

SILVEIRA, Daniel Barile da. Patrimonialismo e a formação do Estado Brasileiro: uma releitura do pensamento de Sergio Buarque de Holanda, Raymundo Faoro e Oliveira Vianna.

SMITH, Richard A. Interest group influence in the U.S. Congress. In: Legislative Studies Quarterly, v. XX, n. 1, p. 89-139, 1995. Disponível em: <http://www.nyu.edu/steinhardt/e/pdf/humsocsci/ mias/readings07/54.pdf>. Acesso em: 08 out. 2012.

SORJ, Bernardo. A nova sociedade brasileira. 2. ed. rev. Rio de Janeiro: Jorge Zahar, 2001.

SOUZA JÚNIOR, Cezar Saldanha. Consenso e democracia constitucional. Porto Alegre: Sagra-Luzzatto, 2002.

WEBER, Max. Ciência e política: duas vocações. Tradução de Leonidas Hegenberg e de Octany Silveira da Mota. São Paulo: Cultrix, 2006. Disponível em: $<$ http://www.fferj.com.br/_arquivos/ documentos/92ac2a1dd30467bb359f82832bd58632.pdf $>$.

ZOVATTO, Daniel. Financiamento dos partidos e campanhas eleitorais na América Latina: uma análise comparada. Opinião Pública, Campinas, v. XI, n. 2, p. 287-336, out. 2005. Disponível em: $<$ http://www.scielo.br/scielo.php?script=sci arttext\&pid= S0104-62762005000200002> Acesso em: 22 set. 2012.

\section{NOTAS}

Artigo elaborado a partir do Trabalho de Conclusão de Curso (TCC) homônimo, apresentado como requisito parcial para obtenção do grau de Bacharel em Direito, na Faculdade de Direito da Pontifícia Universidade Católica do Rio Grande do Sul, e aprovada com nota máxima, com recomendação para publicação, pela Banca Examinadora, composta pelos Prof. Dr. Elton Somensi de Oliveira (orientador), Prof. Me. Jarbas de Melo Lima e Prof. Me. Cláudio Lopes Preza Júnior, em 23 de novembro de 2012

2 BOBBIO, Norberto, MATTEUCCI, Nicola e PARQUINO, Gianfranco. Dicionário de política. 11. ed. Brasília: UNB, 1998, v. 1, p. 392.

3 SOUZA JÚNIOR, Cezar Saldanha. Consenso e democracia constitucional. Porto Alegre: Sagra-Luzzatto, 2002, p. 49-50.

4 BOBBIO, Norberto, MATTEUCCI, Nicola e PARQUINO, Gianfranco. Dicionário de política. 11. ed. Brasília: UNB, 1998, v. 1, p. 392.

5 SELL, Daniel Shaeffer. Estado de Partidos: a solução para a crise de representação política no Brasil. Resenha Eleitoral: nova série, Florianópolis, TRE-4ª Região, v. 15, (ed. esp.), p. 107-129, 2008.

6 Na Inglaterra no Século XVIII as facções encontravam-se ativas, mas o número do eleitorado era muito restrito, tornando desnecessário o planejamento de campanha. Num segundo momento, criaram-se comitês eleitorais para a eleição dos membros da facção, com a aplicação do eleitorado, estes tornaram-se indispensáveis. Ainda, a constituição das facções não abrangia critérios ideológicos, apenas princípios como origem local e interesses comuns. As considerações de cunho ideológico foram relevantes para a constituição do partido, apenas num segundo momento. Em: ARAÚJO, Caetano Ernesto Pereira de. O monopólio dos partidos sobre a representação política. Revista de Informação Legislativa: reforma politica, Brasília, ano 41, n. 161, p 125-131, jan./mar. 2004.

7 SELL, Daniel Shaeffer. Estado de Partidos: a solução para a crise de representação política no Brasil. Resenha Eleitoral: nova série. Florianópolis, TRE-4 $4^{\mathrm{a}}$ Região, v. 15, p. 107-129, ed. esp. 2008.

8 BOBBIO, Norberto, MATTEUCCI, Nicola e PARQUINO, Gianfranco. Dicionário de política. 11. ed. Brasília: UNB, 1998, v. 1, p. 900.

9 BURKE, Edmund. Thoughts in the cause of the presente discontents (1770) em The Works of Edmund Burke. In: CHARLOT, Jean. Os partidos politicos. Brasília: Universidade de Brasília, 1982. Apud: SELL, Daniel
Shaeffer. Estado de Partidos: a solução para a crise de representação política no Brasil. Resenha Eleitoral: nova série, Florianópolis, TRE$4^{\text {a }}$ Região, v. 15, (ed. esp.), p. 107-129, 2008.

10 COUTINHO, Carlos Nelson. GRAMSCI: um estudo sobre seu pensamento político. 3. ed. Rio de Janeiro: Civilização Brasileira, 2007, p. 91 e p. $167-169$.

11 BRASIL. Tribunal Superior Eleitoral. História das Eleições no Brasil. Disponível em: <http://www.tse.jus.br/hotSites/biblioteca/historia das eleicoes/capitulos/partidos politicos/partidos.htm>. Acesso em: $0 \overline{8}$ out 2012.

12 BRASIL. Supremo Tribunal Federal, Pleno, Mandado de Segurança $n^{\circ}$ 26.603/DF, Rel. Min. Celso de Mello, j. 04/10/2007. Disponível em: <http://www.stf.jus.br/portal/processo/verProcessoAndamento. asp?incidente $=2513846>$. Acesso em: 25 out. 2012.

13 MENDES, Gilmar Ferreira; COELHO, Inocêncio Mártires; BRANCO, Paulo Gustavo Gonet. Curso de direito constitucional. 5. ed. rev. atual. São Paulo: Saraiva, 2010, p. 893.

14 MENDES, Gilmar Ferreira; COELHO, Inocêncio Mártires; BRANCO, Paulo Gustavo Gonet. Curso de direito constitucional. 5. ed. rev. atual. São Paulo: Saraiva, 2010, p. 894.

15 COUTINHO, Carlos Nelson. GRAMSCI: um estudo sobre seu pensamento político. 3. ed. Rio de Janeiro: Civilização Brasileira, 2007, p. 93.

16 Inicialmente, caberia definir o sentido desses dois polos, sendo que chegou-se à comunidade em razão do sentido de pluralidade, heterogeneidade, para a linguagem pátria, diferente do termo Povo, não utilizado pelo autor, tendo em vista as contradições ideológicas, podendo significar o conjunto do elemento humano que forma a sociedade política ou o conjunto de seres humanos que se encontram em particular situação socioeconômica. Como Poder, nos detemos ao sentido de "conjunto de seres humanos que possuem a função de mando na sociedade na forma como estão estruturadas e institucionalizadas". SOUZA JÚNIOR, Cezar Saldanha. Consenso e democracia constitucional. Porto Alegre: SagraLuzzatto, 2002, p. 46-47.

17 SOUZA JÚNIOR, Cezar Saldanha. Consenso e democracia constitucional. Porto Alegre: Sagra-Luzzatto, 2002, p. 49-50.

18 Democracia formal é mais um Governo do povo, mas "pode favorecer uma minoria restrita de detentores do poder econômico e, portanto, não ser um poder para o povo, embora seja um Governo do povo [...] 
Indica um certo número de meios que são precisamente as regras de comportamento independentemente dos fins"; Democracia substancial é um Governo para o povo, embora "uma ditadura política possa favorecer em períodos de transformação revolucionária, quando não existem condições para o exercício de uma Democracia formal, a classe mais numerosa dos cidadãos, e ser, portanto, um Governo para o povo, embora não seja um Governo do povo [...] indica um certo conjunto de fins, entre os quais sobressai o fim da igualdade jurídica, social e econômica, independentemente dos meios adotados para os alcançar". BOBBIO, Norberto, MATTEUCCI, Nicola e PARQUINO, Gianfranco. Dicionário de política. 11. ed. Brasília: UNB, 1998, v. 1, p. 328.

19 BOBBIO, Norberto, MATTEUCCI, Nicola e PARQUINO, Gianfranco. Dicionário de Política. 11. ed. Brasília: UNB, 1998, v. 1, p. 327.

20 Trecho retirado de precedente BRASIL. Supremo Tribunal Federal, Pleno. Mandado de Segurança $n^{\circ}$ 26.603/DF, Rel. Min. Celso de Mello, j. 04/10/2007. Disponível em: <http://www.stf.jus.br/portal/processo/ver ProcessoAndamento.asp? incidente $=2513846>$. Acesso em: 25 out. 2012 .

${ }^{21}$ O Partido Comunista Brasileiro (PCB), no começo chamado Partido Comunista do Brasil, foi fundado em março de 1922, com o objetivo de organizar o operariado brasileiro. Influenciado por movimentos grevistas, bem como pela Revolução Russa de 1917 - que em dezembro de 1922 iniciou a formação da União Soviética.

22 SCHLICKMANN, Denise Goulart. Financiamento de campanhas eleitorais. 5. ed. Curitiba: Jiruá, 2010, p. 161.

23 BRASIL. Relatório do projeto de lei para reforma política. Dispõe sobre o sistema eleitoral para as eleições proporcionais e sobre o financiamento público exclusivo das campanhas eleitorais. Brasília, DF: Câmara dos Deputados, 2011. Disponível em: $<$ http://www.henriquefontana.com.br/ henriquefontana/arquivos/folder-projects?folder_id=196040>. Acesso em: 23 set. 2012

${ }^{24}$ RUBIO, Delia Ferreira. Financiamento de partidos e campanhas Fundos públicos versus fundos privados. Novos Estudos CEBRAP, n. 73, p. 5-15, nov. 2005.

25 KATZ, Richard S.; MAIR, Peter. Changing models of party organization and party democracy: the emergency of the cartel party. In: Party Politics, v. 1, n. 1, p. 5-28, 1995. Apud: CAVALCANTE, Carlos Vinicios de Oliveira. $O$ custo da democracia: o financiamento privado das campanhas para o Senado em 2010 e suas implicações à competição política. 2011. 143 f. Dissertação (Mestrado em Ciências Sociais) Faculdade de Filosofia e Ciências Humanas, Pontifícia Universidade Católica do Rio Grande do Sul, Porto Alegre, 2011.

26 SMITH, Richard A. Interest group influence in the U.S. Congress. In: Legislative Studies Quarterly, v. XX, n. 1, p. 89-139, 1995. Disponível em: <http://www.nyu.edu/steinhardt/e/pdf/humsocsci/mias/readings 07/54.pdf $>$. Acesso em: 08 out. 2012.

27 POTTERS, Jan; SLOOF, Randolph. Interest groups: A survey of emprirical models that try to assess their influence. In: European Journal of Political Economy, v. 12, p. 412, 1996. Disponível em: <http://arno. uvt.nl/show.cgi?fid=59708>. Acesso em: 08 out. 2012 .

28 RUBIO, Delia Ferreira. Financiamento de partidos e campanhas Fundos públicos versus fundos privados. Novos Estudos CEBRAP, n. 73 , p. $5-15$, nov. 2005.

29 Tais exemplos referem-se à legislação brasileira. MENDES, Gilmar Ferreira; COELHO, Inocêncio Mártires; BRANCO, Paulo Gustavo Gonet. Curso de direito constitucional. 5. ed. rev. atual. São Paulo: Saraiva, 2010, p. 920-925.

30 ZOVATTO, Daniel. Financiamento dos partidos e campanhas eleitorais na América Latina: uma análise comparada. Opinião Pública, Campinas, v. XI, n. 2, p. 287-336, out. 2005. Disponível em: <http://www.scielo.br/ scielo.php?script $=$ sci arttext\&pid $=$ S0104-62762005000200002>.

31 WOLDENBERG, J. Relevancia y actualidad de la contienda políticoelectoral. In: CARRILLO, M. et al. Dinero y contienda politico-electoral. México: Fondo de Cultura Económica, 2003. Apud: ZOVATTO, Daniel. Financiamento dos partidos e campanhas eleitorais na América Latina: uma análise comparada. Opinião Pública, Campinas, v. XI, n. 2, p. 287-336, out. 2005. Disponível em: <http://www.scielo.br/scielo. php?script $=$ sci_arttext\&pid=S0104-62762005000200002 $>$. Acesso em: 22 set. 2012.

32 RUBIO, Delia Ferreira. Financiamento de partidos e campanhas Fundos públicos versus fundos privados. Novos Estudos CEBRAP, n. 73 , p. 5-15, nov. 2005.

33 RUBIO, Delia Ferreira. Financiamiento político en el Cono Sur. In: GRINER, Steven; ZOVATTO, Daniel (Orgs.). De las normas a las buenas prácticas: el desafío del financiamiento político em América Latina. San José de Costa Rica: OEA-Idea, 2004, p. 273.
34 RUBIO, Delia Ferreira. Financiamento de partidos e campanhas: fundos públicos versus fundos privados. Novos Estudos CEBRAP, n. 73, p. 5-15, nov. 2005.

35 BRASIL. Tribunal Superior Eleitoral. Resoluçãon o 23.376. Brasília. Disponível em: <http://www.eleitoralbrasil.com.br/imagens/textos/files/ Resolucao\%20TSE\%2023376\%20-\%20Arrecadacao\%2C\%20gastos $\% 20 \mathrm{e} \% 20$ prestacao\%20de\%20contas.pdf>. Acesso em: 25 out. 2012.

36 Limites de Doação. Eleitoral Brasil. Florianópolis. Disponível em: $<$ http:// www.eleitoralbrasil.com.br/index.php/txt/ler/18>. Acesso em: 17 set. 2012

37 CAVALCANTE, Carlos Vinicios de Oliveira. O custo da democracia: financiamento privado das campanhas para o Senado em 2010 e suas implicações à competição política. 2011. Dissertação (Mestrado em Ciências Sociais) - Faculdade de Filosofia e Ciências Humanas, Pontifícia Universidade Católica do Rio Grande do Sul, Porto Alegre, 2011. p. 97.

38 SORJ, Bernardo. A nova sociedade brasileira. 2. ed. rev. Rio de Janeiro: Jorge Zahar, 2001, p. 1415.

39 STRECK, Lenio Luiz. Hermenêutica jurídica e $(m)$ crise. Uma exploração hermenêutica da construção do Direito. 10. ed. Porto Alegre: Livraria do Advogado, 2011, p. 29.

40 HOLANDA, Sérgio Buarque de. Raizes do Brasil. 5. ed. Rio de Janeiro: Livraria Jose Olympio, 1969, p. 105-106.

${ }^{41}$ BENDIX, Reinhard, Max Weber: um perfil intelectual. Tradução de Elisabeth Hanna e Jose Viegas Filho. Brasilia: UnB, 1986, p. 270-271.

42 FAORO, Raymundo. Os donos do poder: formação do patronato politico brasileiro. 4. ed. Porto Alegre: Globo, 1977, v. 1, p. 4, 8, 171 e 202.

43 SILVEIRA, Daniel Barile da. Patrimonialismo e a formação do Estado brasileiro: uma releitura do pensamento de Sergio Buarque de Holanda, Raymundo Faoro e Oliveira Vianna, p. 11

44 FAORO, Raymundo. Os donos do poder: formação do patronato politico brasileiro. 4. ed. Porto Alegre: Globo, 1977, v. 1, p. 47.

45 MOTA, Guilherme Carlos. Ideologia da cultura brasileira: 1933-1974. 9. ed. São Paulo: Ática, 1994, p. 179.

46 FAORO, Raymundo. Os donos do poder: formação do patronato político brasileiro. 3. ed. Porto Alegre, 1976, v. 2, p. 740.

47 Ibidem, p. 744.

48 SORJ, Bernardo. A nova sociedade brasileira. 2. ed. rev. Rio de Janeiro. Jorge Zahar, 2001, p. 13.

49 BOURDOUKAN, Adla Youssef. O bolso e a urna: financiamento político em perspectiva comparada.2009. 152 f. Tese (Doutorado em Ciência Política) - Departamento de Ciência Política da Faculdade de Filosofia, Letras e Ciências Humanas, Universidade de São Paulo, São Paulo, 2009.

50 RAMAYANA, Marcos. Direito eleitoral. 8. ed. Niterói-RJ: Impetus, 2008, p. 817

51 FLEISHER, David. Reforma política e financiamento das campanhas eleitorais. In: SPECK, Bruno Wilheilm; ABRAMO, Cláudio Weber; SILVA, Marcos Fernandes G. da; FLEISHER, David; NASSMACHER, Karl Heinz. (Orgs.). Os custos da corrupção. São Paulo: Fundação Konrad Adenauer Stiftung, 2000. (Cadernos Adenauer, 10, p. 79-103).

52 MAINWARING, Scott. Políticos, partidos e sistemas eleitorais: o Brasil num perspectiva comparativa. Tradução de Otacílio F. Nunes Jr. Estudos Eleitorais, Brasília: TSE, v. 1, n. 2, p. 335-381, maio/ago. 1997.

53 Ibidem.

$54 \mathrm{O}$ clientelismo é fruto da relação excessivamente personalizada que por vezes se estabelece entre o eleitor e o candidato, sem a intermediação partidária. É prática eleitoreira de privilegiar um conjunto de indivíduos em troca de seus votos. INSTITUTO ANTÔNIO HOUAISS DE LEXICOGRAFIA. Míni dicionário Houaiss da língua portuguesa. Rio de Janeiro: Objetiva, 2010, 956 p.

55 MANSUR, Vinícius. Decisão sobre o Código Florestal é adiada. Carta Maior. São Paulo-SP, em 25.04.2012. Disponível em: <http://www cartamaior.com.br/templates/materiaMostrar.cfm?materia_id=20028>. Acessado em: 15 out. 2012.

56 BRASIL. Constituição da República Federativa do Brasil de 1988. Brasília, DF: Senado Federal, 1988. Disponível em: <http://www planalto.gov.br/ccivil 03/constituicao/ConstituicaoCompilado.htm>. Acesso em: 23 out. $20 \overline{1} 2$.

57 HESSE, Konrad. Elementos de Direito Constitucional da República Federal da Alemanha. Tradução de Dr. Luís Afonso Heck. 20. ed. Porto Alegre, Sergio Antônio Fabris Editor. 1998, p. 152. (Original: Grundzüge des Verfassungsrechts der Bundesrepublik Deutschland).

58 PORTUGAL, Adriana Cuoco. Lobby pré-eleitoral e financiamento público de campanhas eleitorais: uma exploração em economia política positiva. 2006. 150 f. Tese (Doutorado em Ciências Econômicas) Faculdade de Economia, Administração, Contabilidade e Ciência da Informação e Documentação, Universidade de Brasília, Brasília, DF, 2006. 